\title{
LAMINAÇÃO DE CHAPAS GROSSAS DA GERDAU*
}

\author{
Rafael Abreu Fraga ${ }^{1}$ \\ Rodney Pardo Alves ${ }^{2}$ \\ Flávio Viana de Freitas ${ }^{3}$ \\ Emanuelle Garcia Reis ${ }^{4}$ \\ Maurício Martins Pereira ${ }^{5}$ \\ José Herbert Dolabela da Silveira ${ }^{6}$
}

\section{Resumo}

Este trabalho tem como objetivo apresentar a nova linha de Laminação de Chapas Grossas da Usina de Ouro Branco da Gerdau, marcando a entrada da empresa na produção de chapas grossas de alto valor agregado no Brasil. A primeira fase do projeto consiste de um forno de reaquecimento de placas, um laminador de chapas grossas, sistema de resfriamento acelerado - Mulpic ${ }^{\circledR}$, desempandeiras a quente e a frio e uma completa linha de acabamento constituída de linha de tesouras, oxi corte e máquina de ultra som. Neste projeto estão empregadas as mais modernas tecnologias para garantir a qualidade do produto: automação completa dos equipamentos com modelos matemáticos de controle do processo, sistema HAGC, Work Roll Bending e Work Roll Shiftting Smart Crown®. A nova linha tem capacidade de produção de 1,2 milhões de toneladas por ano na primeira fase, podendo alcançar 1,8 milhões de toneladas na segunda fase com espessura variando entre 6,0 a $150 \mathrm{~mm}$ e largura entre 900 a $3700 \mathrm{~mm}$.

Palavras-chave: Laminação de chapas grossas; Chapa Grossa; Produto laminado.

\section{Abstract}

\section{THE NEW GERDAU PLATE MILL}

This paper intends to present the new line of Gerdau Plate Mill which is currently under construction in Ouro Branco Works, marking the company's entry in the production of plates in Brazil. The first stage of the project consists in a Reheating Furnace, Plate Mill single stand, Acelerated Cooling System type Mulpic® and Hot/Cold Levelers and complete finishing lines with shears, gas cutting areas and UST machine. In this project are being employed the latest technologies to ensure product quality: full automation of equipment with mathematical models for process control, H-AGC systems, Work Roll Bending and Work Roll Shiftting with Smart Crown technology. The new line will have a production capacity of 1,2 million tons per year in the first stage, reaching 1.8 million tons in the second stage with a thickness ranging from 6.0 to $150 \mathrm{~mm}$ and width from 900 to $3700 \mathrm{~mm}$ in the second stage.

Key Words: Plate mill; Heavy Plate; Flat product.

1 Sócio da ABM, Engenheiro Metalurgista, M.B.A.- Assessor Técnico da Laminação de Chapas Grossas da Gerdau.

2 Sócio da ABM, Engenheiro Metalurgista, M.B.A.- Chefe de Área da Laminação de Chapas Grossas da Gerdau.

3 Sócio da ABM, Engenheiro Metalurgista, M.B.A.- Assessor Técnico da Laminação de Chapas Grossas da Gerdau.

4 Sócia da ABM, Engenharia Civil, M.Eng - Assessor Técnico da Laminação de Chapas Grossas da Gerdau.

5 Sócio da ABM, Engenheiro Metalurgista, M.B.A.- Assessor Técnico da Laminação de Chapas Grossas da Gerdau.

6 Sócio da ABM, Engenheiro Metalurgista, M.Eng., M.B.A, - Gerente da Laminação de Chapas Grossas da Gerdau. 


\section{INTRODUÇÃO}

A Gerdau mostra neste trabalho o maior investimento de sua centenária história que é a nova linha de Laminação de Chapas Grossas em Ouro Branco - MG, visando atender as mais exigentes condições de mercado brasileiro e mundial através da obtenção de produtos com excelente homogeneidade de propriedades mecânicas, sanidade interna, planicidade e uniformidade de espessura.

Os produtos serão destinados principalmente à fabricação de produtos para aplicação nos setores de geração de energia, óleo e gás, construção civil, maquinários pesados, naval e vasos de pressão. Além disso, a Gerdau visa atuar no iminente mercado de óleo e gás, estando preparada para atender às demandas que serão geradas pelos investimentos nesse setor no Brasil e no mundo.

\section{DESENVOLVIMENTO}

O novo laminador de Chapas Grossas da Gerdau possuí o chamado "Estado da Arte" em tecnologia de seus equipamentos e processos. Uma concepção próxima de 900 metros de comprimento com capacidade de 1,2 milhões t/ano de chapas grossas nas espessuras entre 6,0 e 150 mm e larguras entre 900 e 3700 mm [2].

A linha de laminação é composta por um Forno de Reaquecimento de Placas de 220/265 t/h, um Laminador de Chapas Grossas do tipo 4Hi, um Sistema de Resfriamento Acelerado - Mulpic $®$ e Desempenadeiras a Quente. A linha de acabamento é composta por uma Linha principal totalmente automatizada está equipada com Tesoura Lateral e Tesoura Divisora, Área de Inspeção e Desempenadeira a Frio, Ultra Som e Oxi Corte;

O plano de implantação dessa nova linha de laminação a quente é composto, também, por uma Oficina de Cilindros acoplada a linha de laminação.

O projeto da nova linha de laminação está divido em duas fases distintas, onde a primeira fase irá iniciar com capacidade de produção de 1,2 milhões de toneladas por ano, podendo alcançar 1,8 milhões de toneladas na segunda fase do projeto [2]. As Figuras 1 e 2 apresentam o layout geral da nova linha de chapas grossas da Gerdau Ouro Branco e seus principais equipamentos contemplados nas duas fases de implantação [2].

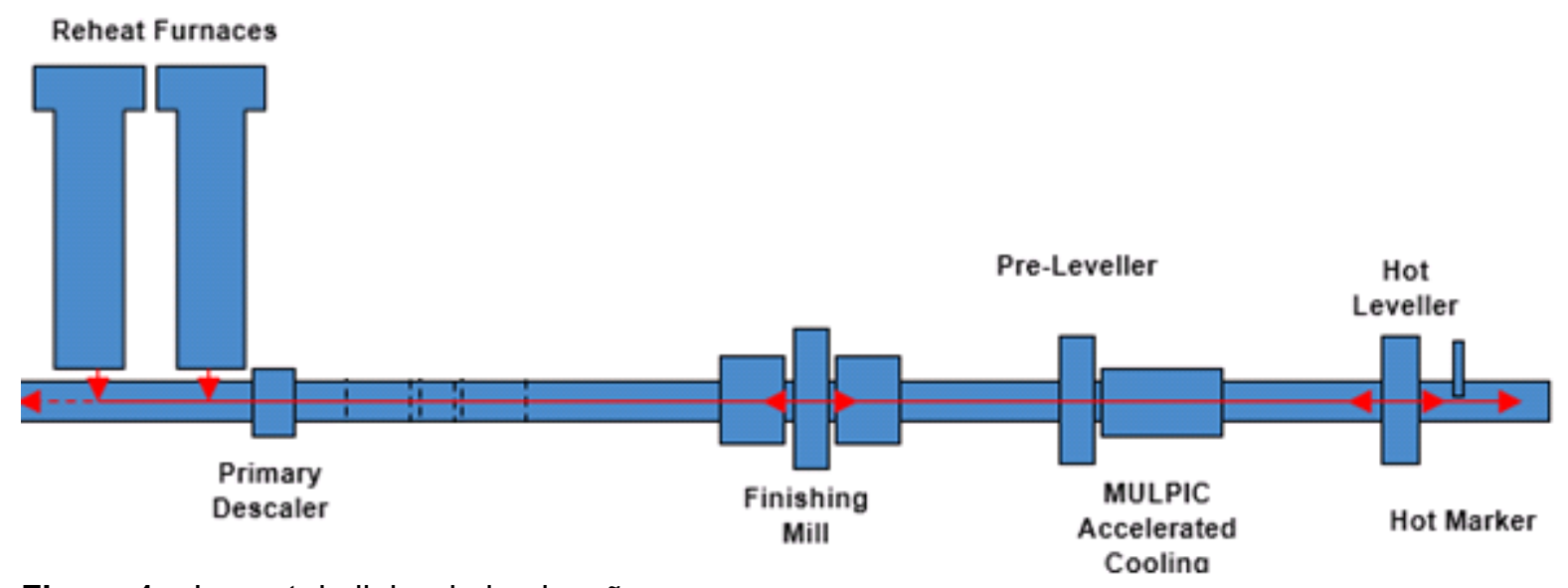

Figura 1 - Layout da linha de laminação 


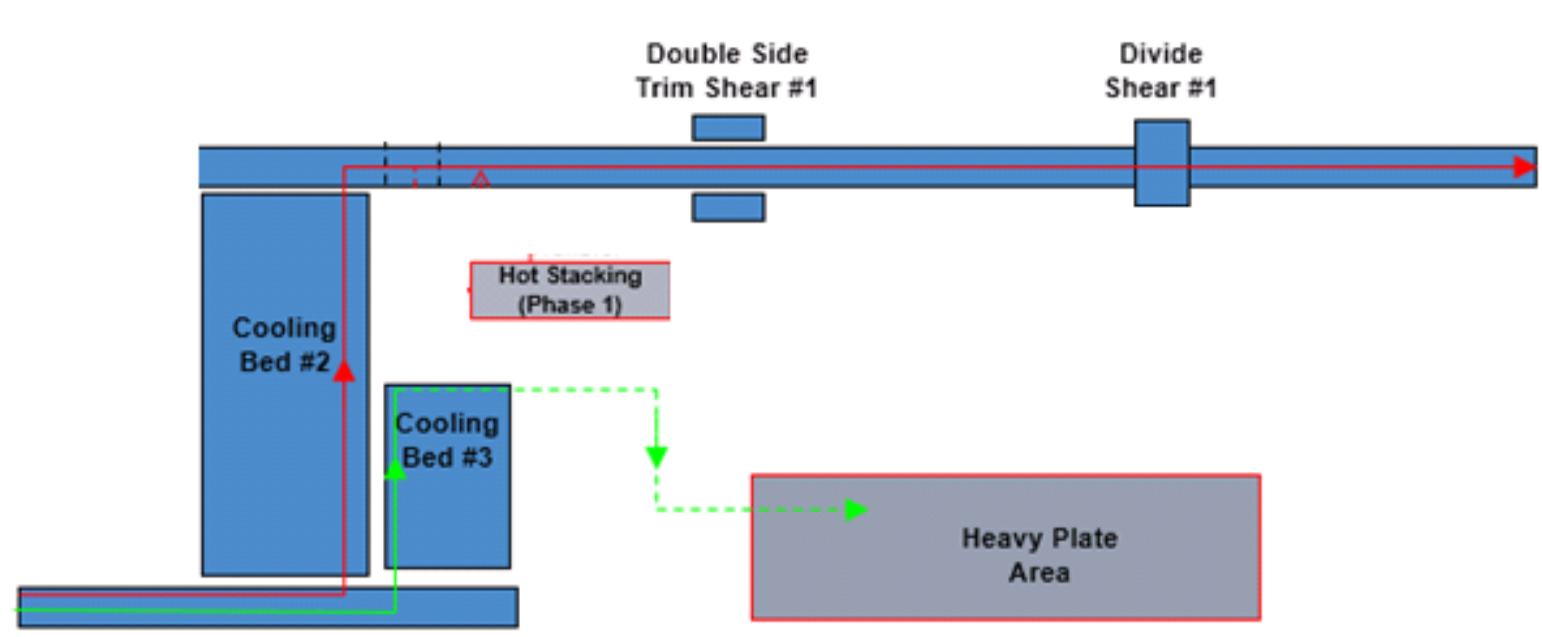

Figura 2.1 - Layout da linha de acabamento

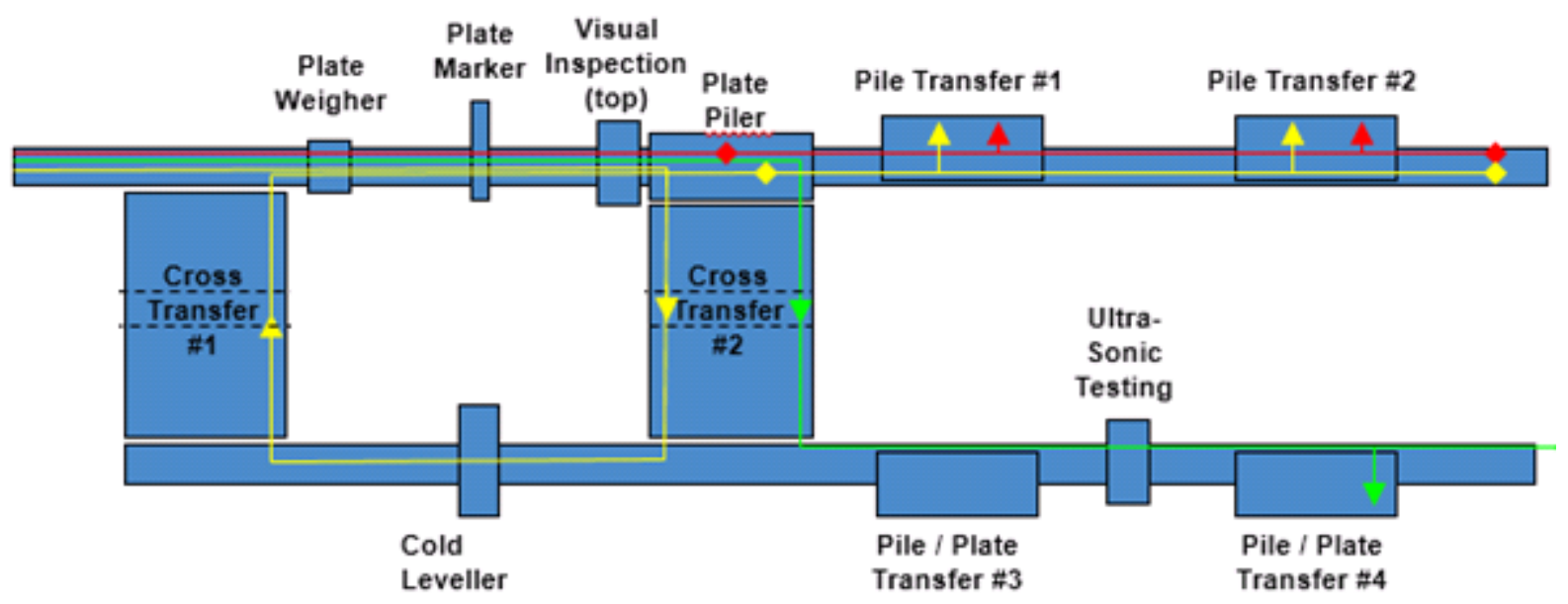

Figura 2.2 - Layout da área de inspeção, Desempenadeira a Frio e Ultra Som

A seguir serão apresentados os principais equipamentos da linha de laminação a quente.

\subsection{FORNO DE REAQUECIMENTO}

A qualidade da chapa grossa começa nos Fornos de Reaquecimento, onde as placas devem ser reaquecidas de forma uniforme com um perfil de temperatura apropriado para obtenção de propriedades mecânicas e metalúrgicas requeridas durante sua laminação. Para tanto, é desejável um controle dinâmico e automático das temperaturas para que se reduza, também, o consumo de combustível, uma vez que esse item é responsável por uma grande parcela dos custos de operação do processo de laminação a quente [1].

Para obter tal desempenho, a nova linha de laminação a quente conta com um forno de reaquecimento de placas tipo walking beam, totalmente automatizado, com sistema de modelamento matemático para otimização das temperaturas de aquecimento e do consumo de combustível. Além da tecnologia de combustão Flameless (sem chama), onde o regime de combustão é caracterizado pela ausência de chama [1]. A Tabela 1 apresenta as principais características do forno de reaquecimento de placas. 
Tabela 1. Características do Forno de Reaquecimento

Tipo

Capacidade

Comprimento útil

Largura útil

Dimensões da Placa

Combustível

Walking Beam

$220 \mathrm{t} / \mathrm{h}$

$56.200 \mathrm{~mm}$

$8000 \mathrm{~mm}$

220 e $250 \mathrm{~mm}$

900 a $2100 \mathrm{~mm}$

2200 a $7500 \mathrm{~mm}$

GCO, GAC e/ou GN

Fornecedor

LOI - ITALIMPIANTI

\subsection{DESCAREPAÇÃO}

Para obter uma superfície isenta de carepas, a nova linha de laminação a quente conta com um Sistema de Descarepação totalmente automatizado e com elevada capacidade de remoção de carepa através do impacto de jatos de água com bicos de alto impacto [2].

A Tabela 2 apresenta as principais características do Sistema de Descarepação Primária.

Tabela 2. Características do Descarepador Primário

\begin{tabular}{|l|l|}
\hline Tipo & Hidráulico \\
\hline Pressão de descarepação & 250 bar \\
\hline Quantidade de Headers & 2 superiores e \\
& 2 inferiores \\
\hline Quantidade de bicos & 26 em cada header \\
\hline Ajuste de altura & Automático \\
\hline Fornecedor & Ebara \\
\hline
\end{tabular}

\subsection{LAMINADOR}

A linha conta com um laminador de chapas grossas do tipo $4 \mathrm{HI}$, responsável pelas fases de desbaste e acabamento do laminado. Este laminador é equipado com modernos recursos para obtenção de forma e espessura homogênea ao longo do laminado durante as fases de processamento [2]:

- Work Roll Bending,

- Work Roll Shiftting,

- Plan View Control

- Perfil dos Cilindros tipo Smart Crown

- Automatic Gauge Control do tipo hidráulico

Além de modelos matemáticos de setup dos equipamentos e modelo de temperatura integrado, necessários para um maior controle dos parâmetros de processo.

A Tabela 3 apresenta as principais características da Cadeira de Laminação: 
Tabela 3. Características do Laminador

Tipo

$4 \mathrm{HI}$

\section{Cedagem}

Mesa dos Cilindros de Trabalho

Diâmetro de Cilindros de Trabalho

Mesa dos Cilindros de Encosto

Diâmetro de Cilindros de Encosto

Força máxima de laminação

Força do Work Roll Bend

SmartCrown®

Potência dos Motores

Torque Nominal

Velocidade máxima

Fornecedor
$900 \mathrm{t} / \mathrm{mm}$

$4100 \mathrm{~mm}$

Ø $1120-1020 \mathrm{~mm}$

$3800 \mathrm{~mm}$

$\varnothing 2200-2100 \mathrm{~mm}$

$8500 \mathrm{t}$

$400 \mathrm{t} /$ mancal

$\pm 150 \mathrm{~mm}$ para SmartCrown®

2 x 8500kW @ 0 / 80 / 250 rpm.

$3690 \mathrm{kNm} /$ alonga

$7,2 \mathrm{~m} / \mathrm{s}$

Primetals Technologies

A Figura 3 ilustra o Laminador de Chapas Grossas:

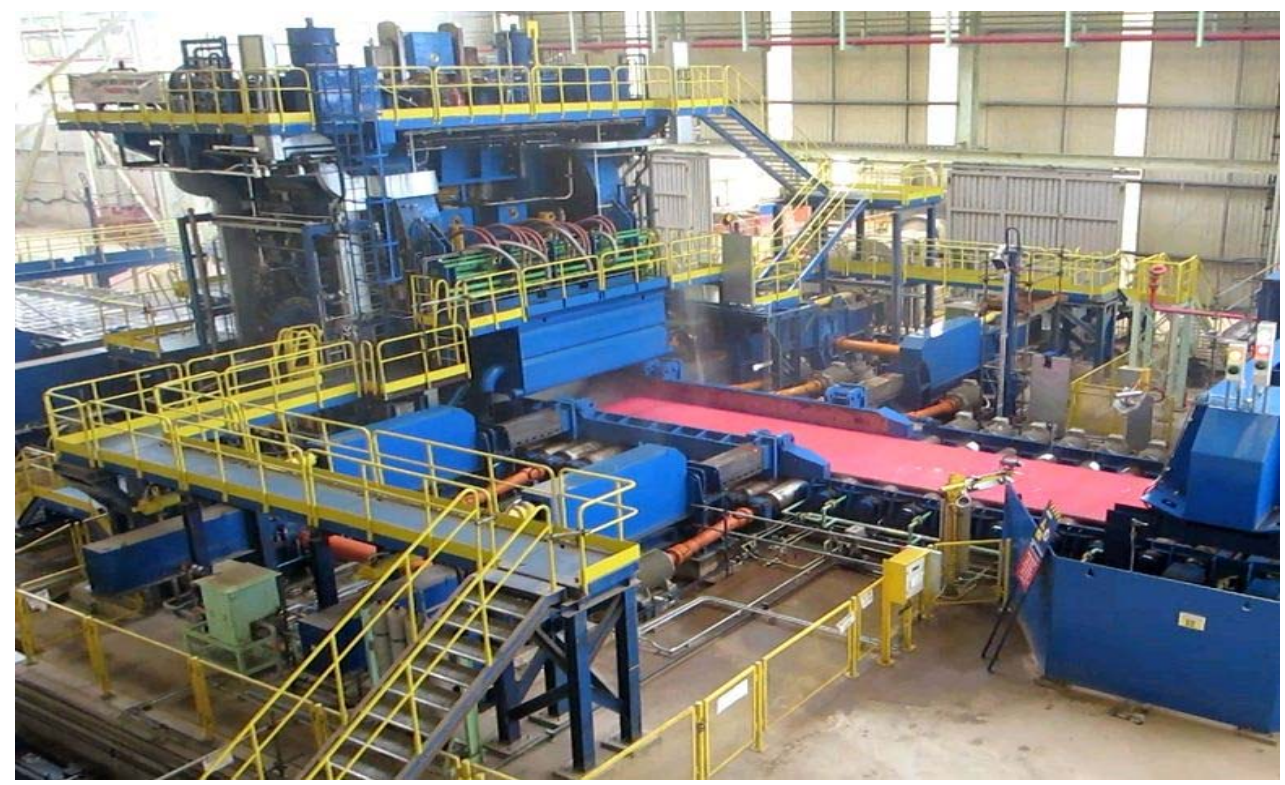

Figura 3 - Foto do laminador de chapas grossas

\subsection{CONTROLE DE ESPESSURA}

O modelo matemático do esquema de passes junto com o HAGC - Hydraulic Automatic Gauge Control são os responsáveis pela obtenção e controle da espessura do laminado com tolerâncias restritas.

O HAGC é do tipo curso longo e possui resposta rápida para atuação precisa no exato ponto de aplicação.

Outra inovação tecnológica proporcionada pelo dueto modelo/HAGC é a laminação de chapas com múltiplas espessuras ao longo do comprimento da chapa. Essas chapas são aplicadas principalmente nos setores naval e construção de grandes estruturas metálicas como pontes. Os principais benefícios para o cliente são a redução de custos com soldagem e uniões e rapidez na montagem. A figura 4 
mostra alguns dos perfis de espessura ao longo do comprimento da chapa possíveis de serem obtidos:

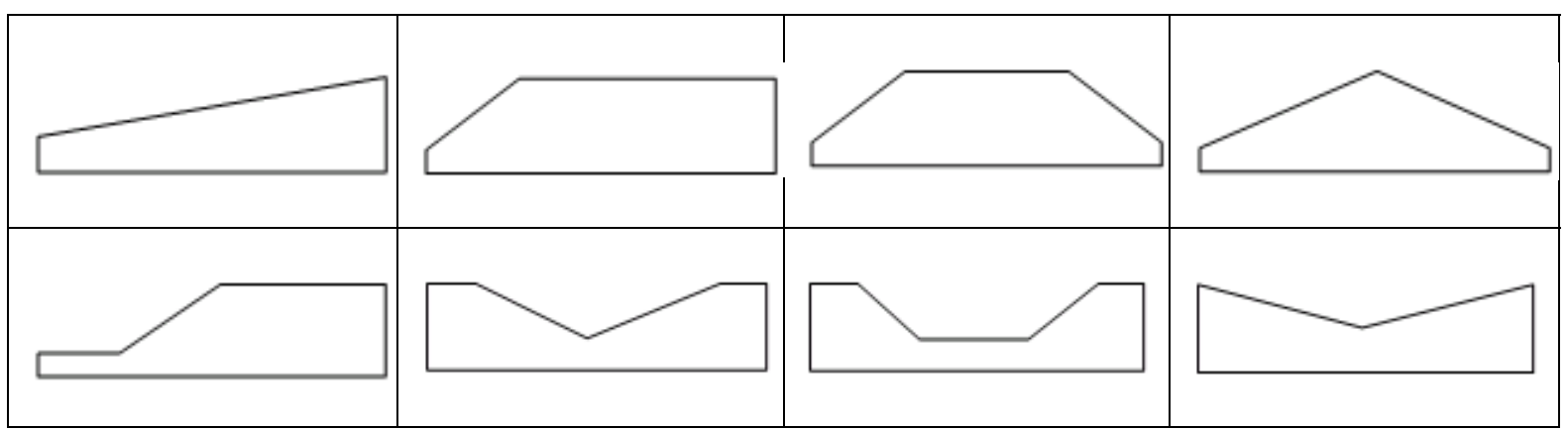

Figura 4 - Perfis possiveis de serem laminados

\subsection{CONTROLE DE PLANICIDADE}

\subsubsection{Work roll bending}

O Work Roll Bending é utilizado durante os passes de laminação para compensar as variações na carga de laminação, mantendo o coroamento relativo da chapa. Para o processo de laminação, esta correção é mais evidente e mais necessária nas extremidades do esboço, em função da diferença de carga a maior nesta região devido a menor temperatura.

O modelo matemático calcula a carga de laminação e a flexão dos cilindros de trabalho e então prevê uma carga necessária de Work Roll Bending para possibilitar as correções durante o passe de laminação [2].

\subsubsection{Work Roll Shifting com Smart Crown®}

O Work Roll Shiftting com Smart Crown ${ }^{\circledR}$ é usado para ajustar o coroamento mecânico do cilindro de trabalho antes do início do passe. A posição do Work Roll Shiftting é calculada pelo modelo matemático como parte do plano de reduções para obter o coroamento objetivado no material. Isto permite que toda a faixa de atuação do bending seja usada apenas para manter o coroamento relativo entre passes quando da variação da carga de laminação em relação à carga prevista.

O Work Roll Shiftting com Smart Crown ${ }^{\circledR}$ também é usado para compensar o desgaste do cilindro de trabalho, possibilitando estender a campanha do cilindro no laminador [2]. A Figura 5 mostra o princípio básico do perfil do cilindro de trabalho para uso no Smart Crown®:
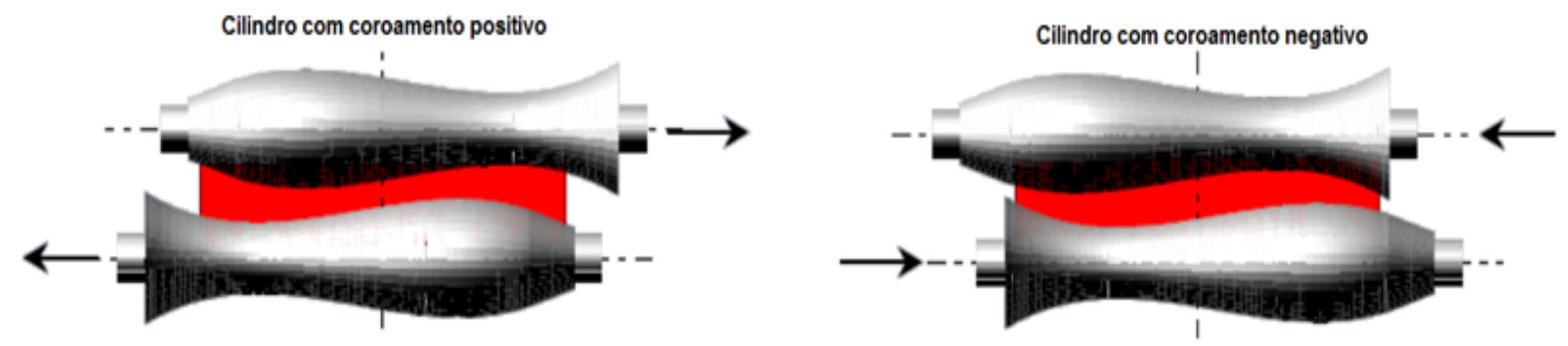

Figura 5 - Perfil smart crown com work roll shifting. 


\subsection{CONTROLE DE FORMA}

O formato do esboço está diretamente ligado a perdas pelo qual o material passará na linha de acabamento. Em resumo quanto mais retangular a forma do esboço menor serão seus descartes e consequentemente melhor rendimento metálico. O laminador possui um modelo matemático especifico para este fim, denominado PVPC $®$ - Plan View Pattern Control. Através da sua incorporação ao modelo de esquema de passes é possível obter um perfil de espessura variável no passe inicial e de alargamento permitindo um esboço sem a formação de pontas excessivas;

A figura 6, ao lado, ilustra os passes onde são aplicados o perfil variável de espessura para controle da forma

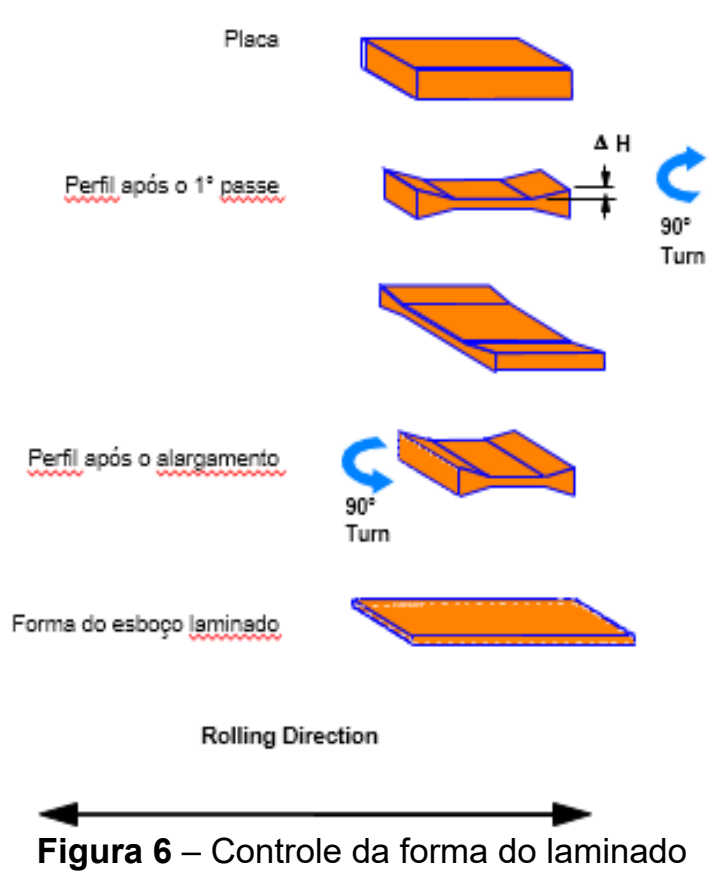

\section{RESFRIAMENTO ACELERADO - Mulpic ${ }^{\circledR}$}

O sistema de resfriamento fica situado na mesa de saída do laminador é composto por uma Pré Desempenadeira na entrada e uma unidade de resfriamento com quatro bancos de resfriamento capaz de promover dois tipos de resfriamento: acelerado (ACC) e tempera direta (DQ).

A Pré desempenadeira tem a responsabilidade de conferir planicidade ao material antes de passar pelo processo de resfriamento. Cada estratégia de resfriamento é selecionada de acordo com as propriedades mecânicas requeridas específicas para cada tipo de aplicação.

A figura 7 mostra o sistema de Resfriamento de Chapas:

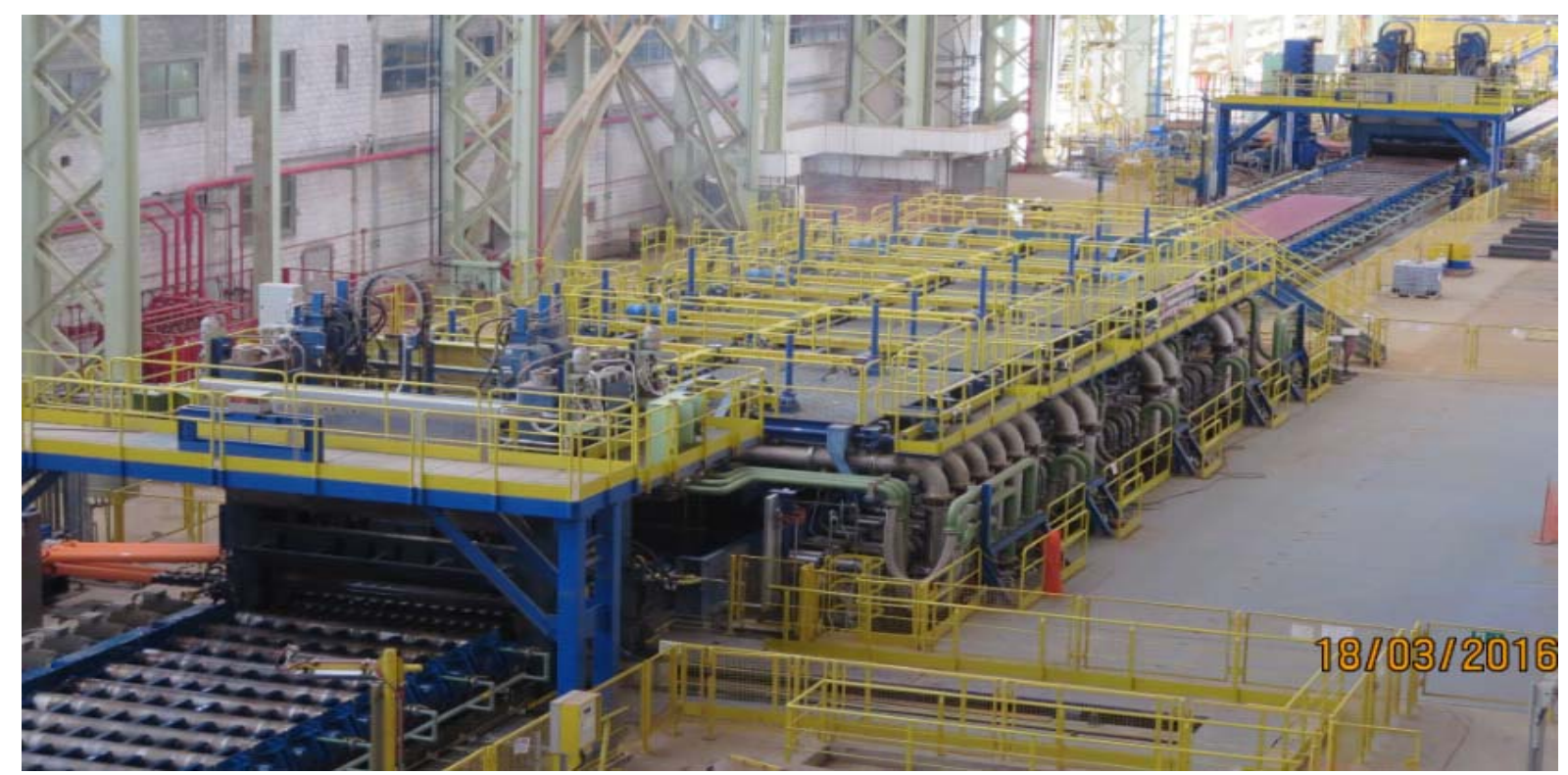

Figura 7 - Pré Desempenadeira junto ao Sistema de Resfriamento 
Tabela 6. Características da Pré Desempenadeira

Tipo

$4 \mathrm{Hi}$ - Hidraulica

Número de rolos

Diâmetro

Força

Motor

Velocidade

Fornecedor
5 (3 superiores, 2 inferiores)

$280 \mathrm{~mm} / 270 \mathrm{~mm}$

1200 ton

$1 \times 450 \mathrm{~kW}$

$2.0 \mathrm{~m} / \mathrm{s}$

Primetals Technologies

Tabela 7. Características do Mulpic

Tipo

Número de bancos

Números de bicos

Máxima densidade e Vazão de água

\section{Fornecimento de água}

Ajuste de Altura dos bancos

Edge Masking

Fornecedor
MULPIC Plate Cooling System

4 bancos com 6 headers cada divididos em em superior e inferior ao longo de 24 metros 910 por header

Banco A

- ACC - nominal $15 \mathrm{l} / \mathrm{sec} / \mathrm{m}^{2}-11,360 \mathrm{~m}^{3} / \mathrm{h}$

- $\quad D Q$ - nominal $33 \mathrm{l} / \mathrm{sec} / \mathrm{m}^{2}-11,930 \mathrm{~m}^{3} / \mathrm{h}$

Bancos B, C, D

- ACC - nominal $15 \mathrm{l} / \mathrm{sec} / \mathrm{m}^{2}$

$A C C$ - tanque elevado

$D Q$ - banco A Sistema de bombas

Ajuste automático eletro mecânico

By electrically operated screw-jacks

Primetals Technologies

\section{DESEMPENADEIRA}

Visando conferir planicidade ao material laminado e resfriado, uma potente Desempenadeira a Quente equipada com Work Roll Bending está localizada ao final da linha de laminação. A figura 8 mostra a Desempenadeira a Quente:

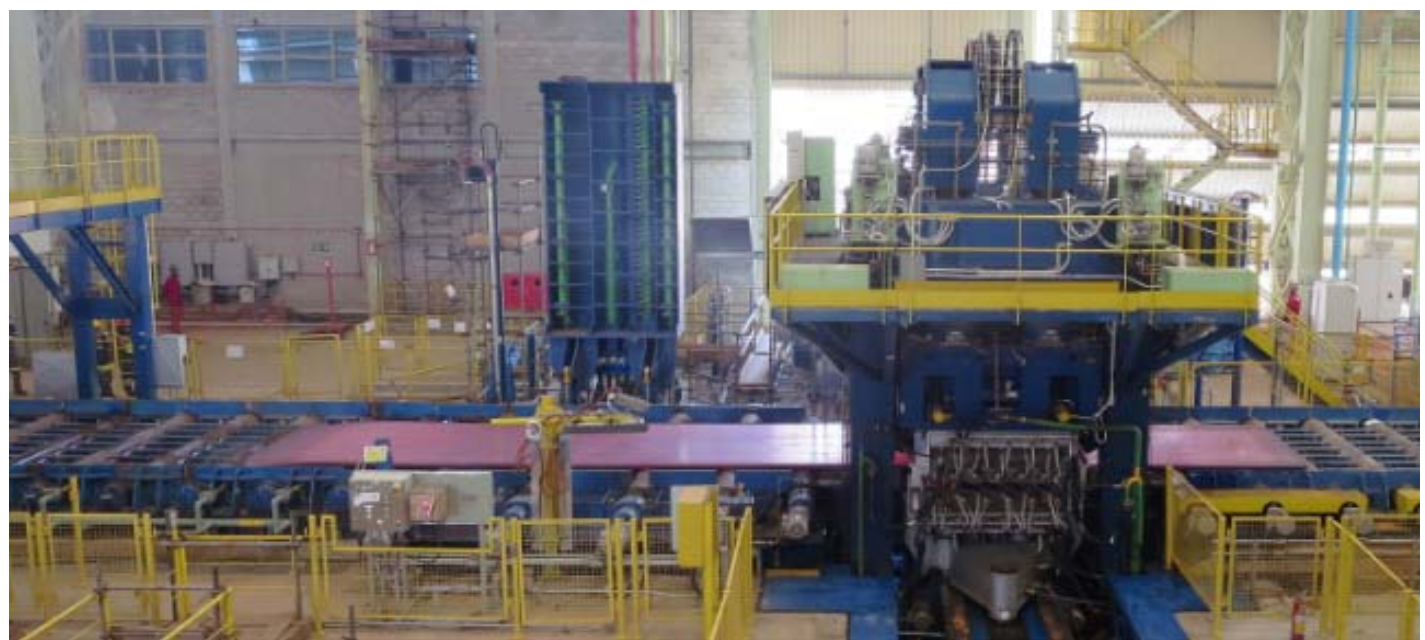

Figura 8 - Desempenadeira a Quente 
$\mathrm{Na}$ entrada do equipamento ainda há uma unidade de descarepação para remoção de eventuais carepas remanescentes no esboço;

Tabela 8. Características da Desempenadeira a Quente

\begin{tabular}{ll} 
Tipo & $4 \mathrm{Hi}-$ Hidraulica \\
\hline Número de rolos & $11(6$ superiores, 5 inferiores $)$ \\
\hline Diâmetro & $280 \mathrm{~mm} / 270 \mathrm{~mm}$ \\
\hline Força & $3000 \mathrm{ton}$ \\
\hline Motor & $11 \times 160 \mathrm{~kW}$ \\
Velocidade & $2.0 \mathrm{~m} / \mathrm{s}$ \\
\hline Curso Bending & $50 \mathrm{~mm}$ \\
\hline Pressão Descarepação & 140 bar \\
\hline Fornecedor & Primetals Technologies
\end{tabular}

\section{LINHA DE TESOURAS}

A linha de acabamento composta pelas Tesouras Lateral e Tesoura Divisora são os principais equipamentos. Ainda existe uma área completa para inspeção minuciosa da qualidade das chapas composta por Máquina de Marcação Automática, Balança e Desempenadeira a Frio On Line.

Tabela 9. Características da Tesoura Lateral

\begin{tabular}{|l|l|}
\hline Tipo & Three Crank - Corte Mecânico \\
\hline Força & $650 \mathrm{t}$ \\
\hline Espessura máxima & $40 \mathrm{~mm}$ com1200 Mpa de resistência \\
\hline Tempo de ciclo & $50 \mathrm{~mm}$ com700 Mpa de resistência \\
\hline Taxa de corte & Approx. $2 \mathrm{seg}$ \\
\hline Minima apara & 30 cortes $/ \mathrm{min}$. \\
\hline Fornecedor & $20 \mathrm{~mm}$ \\
\hline
\end{tabular}

Tabela 10. Características da Tesoura Divisora

\begin{tabular}{|l|l|}
\hline Tipo & Two Crank - Corte Mecânico \\
\hline Força & $1600 \mathrm{t}$ \\
\hline Espessura máxima & $40 \mathrm{~mm}$ com1200 Mpa de resistência \\
\hline Tempo de ciclo & $50 \mathrm{~mm}$ com700 Mpa de resistência \\
\hline Máxima apara & Approx. 4,5 seg \\
\hline Fornecedor & $500 \mathrm{~mm}$ \\
\hline
\end{tabular}

A figura 9, mostra as tesouras lateral e divisora: 

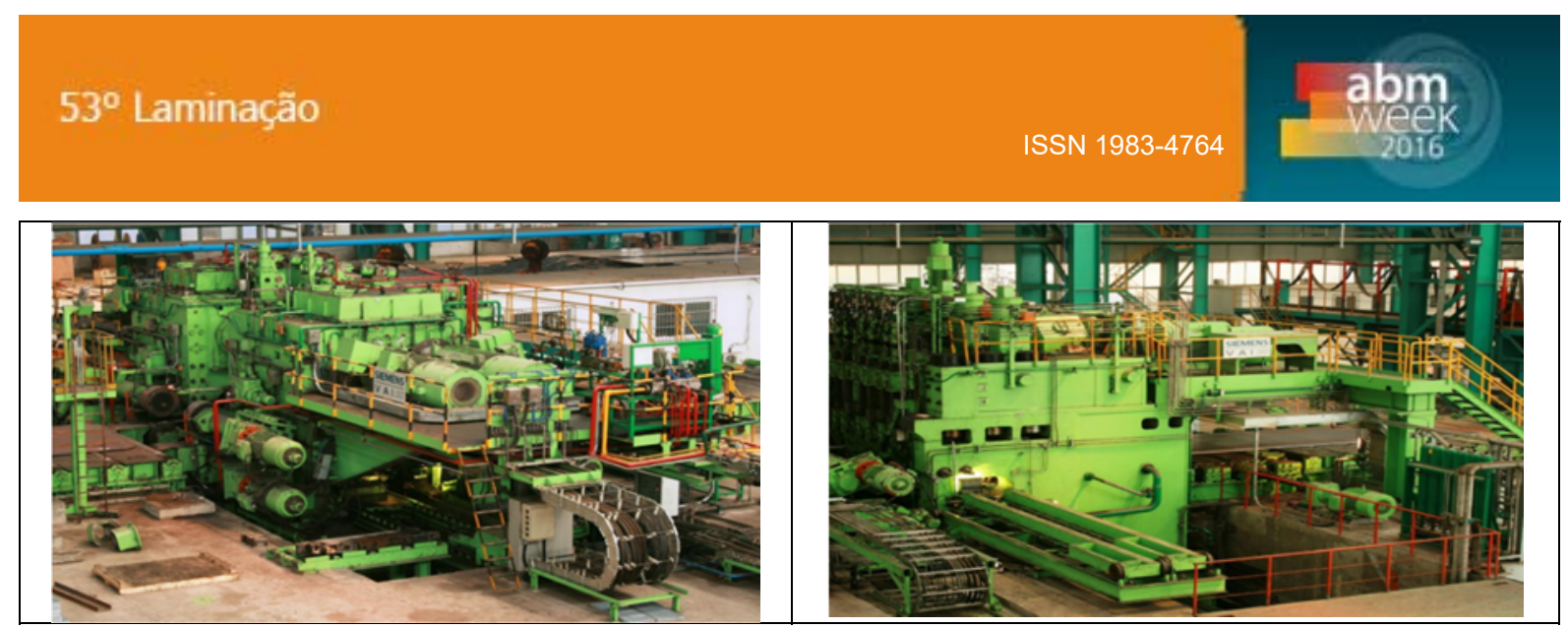

Figura 9 - Tesoura Lateral e Tesoura Divisora

\section{GESTÃO DE PÁTIOS INTERNOS DE PLACA E CHAPA}

Os pátios internos da linha de chapas grossas são gerenciados por sistemas de controle desenvolvidos em parceria com a área de Tecnologia de Informação. Estes sistemas têm como principais funções garantir o rastreamento de placas e chapas estocadas nos pátios, otimizar a estocagem e minimizar a movimentação interna de material. Outro fator significativo do projeto é a localização da linha de chapas grossas em relação à aciaria. A linha foi construída em frente da aciaria que facilitará o enfornamento de placas quentes (Hot Charge) visando a redução do consumo de combustíveis utilizados nos fornos de reaquecimento e redução do lead time dos pedidos em produção. A figura 10 mostra a posição relativa da Aciaria e o Laminação de Chapas Grossas da usina de Ouro Branco:

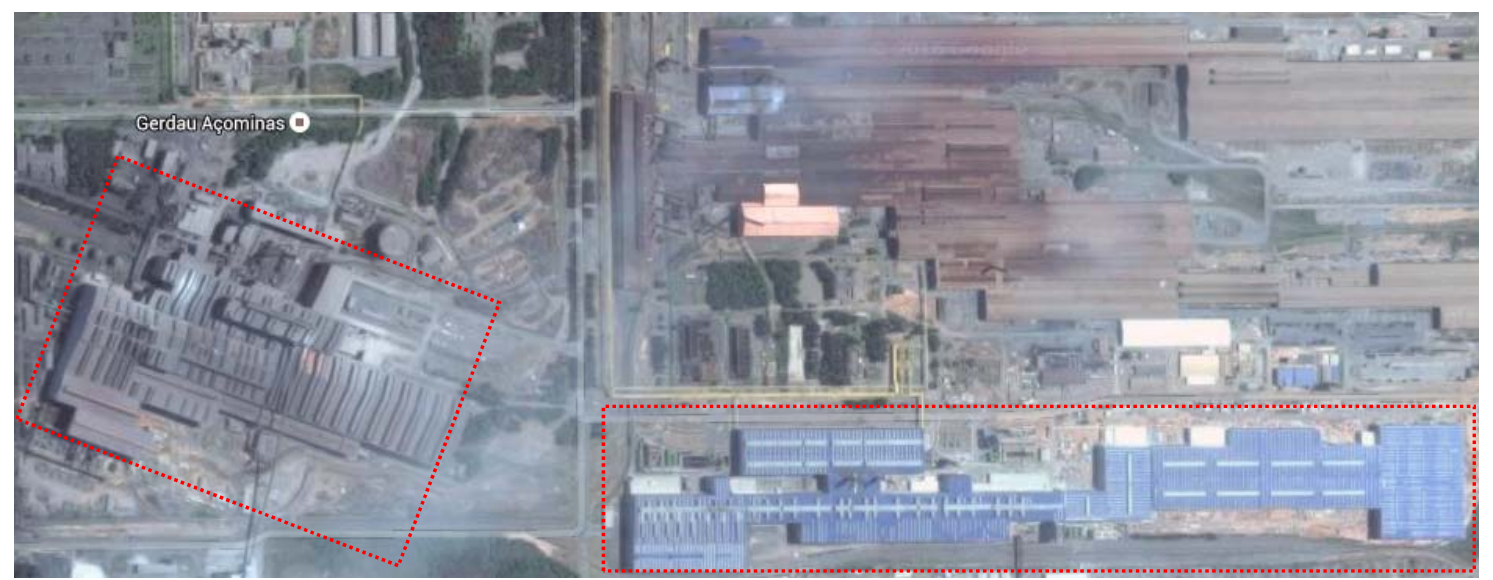

Figura 10 - Aciaria e Laminação de Chapas Grossas da Usina de Ouro Branco

\section{CONCLUSÃO}

A realização desse projeto é parte de um grande plano de investimentos da Gerdau visando aumentar seu portfólio de produtos. Devido ao elevado grau de automação e das novas tecnologias implantadas, as perdas no processo e a geração de defeitos serão minimizadas e a produtividade maximizada. Desta forma a Gerdau conquistará posição de destaque no mercado de laminados planos assim como já faz em produtos longos.

\section{REFERÊNCIAS}

1 LOI Italimpianti - Gerdau - Technical Specification 265 t/h Walking Beam Reheating Furnace. 2010.

2 Siemens VAI. Technical Specification for Plate Mill Plant for Gerdau Ouro Branco. 2010. 